\title{
sCD14 is not a bona-fide biomarker of microbial translocation in HIV-1-infected Africans living in Belgium
}

\author{
Adrien De Voeght, Nathalie Maes and Michel Moutschen
}

Objective: To compare microbial translocation and its biomarkers in HIV-1-infected African and White patients of the Liège AIDS Reference Center.

Design: The study is based on a cross-sectional dataset of HIV-infected patients treated at the Liège AIDS Reference Center. Groups of white and African patients have been randomly selected to be identical for sex, age and duration of treatment.

Methods: sCD14, lipopolysaccharide (LPS), lipopolysaccharide-binding protein (LBP) and routine HIV-follow-up parameters were measured on plasma samples.

Results: High values of LPS and LBP were observed in both groups of patients without significant difference between them. High values of sCD14 were observed in $53.1 \%$ of whites and only in $18.8 \%$ of African patients $(P=0.0042)$. A correlation between LPS and sCD14 was observed in whites but not African patients.

Conclusion: Our observation suggests that factors not related to microbial translocation are responsible for lower sCD14 value in Africans.

Copyright $\odot 2016$ Wolters Kluwer Health, Inc. All rights reserved.

AIDS 2016, 30:000-000

Keywords: HIV, immune activation, innate immunity, microbial translocation, soluble CD14

\section{Introduction}

The progression of HIV disease is lead both by viral replication and by immune activation whose intensity is in fact is a better predictor of progression to AIDS than virological markers [1].

It is known that HIV infection of the gut-associated lymphoid tissue (GALT) selectively depletes CD $4^{+}$Th17 cells and subsequently impairs intestinal barrier function. Consequently, whole bacteria and microbial products from the intestine enter the systemic circulation, a phenomenon called microbial translocation.
Since years, microbial translocation has been viewed as a possible mechanism underlying the chronic immune activation associated with HIV infection and subsisting despite antiretroviral therapy $[2,3]$.

Microbial translocation is usually evaluated by measuring blood concentration of bacterial lipopolysaccharide (LPS). Nevertheless, measuring LPS concentration is a technically complex process and difficult to implement in routine care. Therefore, there is a need to identify reliable biomarkers of microbial translocation easier to measure than LPS itself.

University of Liège, Liège, Belgium.

Correspondence to Adrien De Voeght, University of Liège, Liège, Belgium.

E-mail: adrien.devoeght@student.ulg.ac.be

Received: 15 September 2015; revised: 30 November 2015; accepted: 30 November 2015.

DOI:10.1097/QAD.0000000000000996

ISSN 0269-9370 Copyright (c) 2016 Wolters Kluwer Health, Inc. All rights reserved. 
AIDS 2016, Vol 00 No 00

Table 1. Comparison of the two ethnic groups (Whites vs. Africans)

\begin{tabular}{|c|c|c|c|}
\hline & White $(N=32)$ & Black African $(N=32)$ & $P$ value $^{\mathrm{a}}$ \\
\hline Male sex & $17(53)$ & $15(47)$ & 0.62 \\
\hline Age (years) & $47 \pm 13$ & $46 \pm 10$ & 0.16 \\
\hline BMI $\left(\mathrm{kg} / \mathrm{m}^{2}\right)$ & $25.1 \pm 1.5$ & $26.5 \pm 1.9$ & 0.31 \\
\hline Absolute $\mathrm{CD}^{+}\left(10^{3}\right.$ cells $\left./ \mu \mathrm{l}\right)$ & $0.67 \pm 0.25$ & $0.55 \pm 0.24$ & 0.28 \\
\hline Absolute CD ${ }^{+}\left(10^{3} \mathrm{cell} s / \mu \mathrm{l}\right)$ & $0.89 \pm 0.44$ & $0.67 \pm 0.29$ & 0.10 \\
\hline$\beta 2$-microglobulin $(\mathrm{mg} / \mathrm{l})$ & $1.50 \pm 3.9$ & $0.27 \pm 0.48$ & 0.74 \\
\hline Patients with high viral load (>200 copies/ml) & $1(1.6)$ & $2(3.1)$ & $0.99^{b}$ \\
\hline C-reactive protein (CRP) $(\mathrm{mg} / \mathrm{l})$ & $5.1 \pm 8.7$ & $5.7 \pm 10.8$ & 0.69 \\
\hline Total cholesterol (g/l) & $2.2 \pm 0.4$ & $2.0 \pm 0.51$ & 0.58 \\
\hline High-density lipoprotein cholesterol (g/l) & $2.8 \pm 10.2$ & $2.5 \pm 8.1$ & 0.42 \\
\hline Non-high-density lipoprotein cholesterol (g/l) & $1.6 \pm 0.48$ & $1.4 \pm 0.5$ & 0.47 \\
\hline Triglycerides (g/l) & $2.2 \pm 2.0$ & $1.4 \pm 1.8$ & 0.026 \\
\hline Gamma glutamyl transpeptidase (GGT) (U/I) & $37.8 \pm 24.2$ & $35.7 \pm 20.0$ & 0.89 \\
\hline Glutamate-oxaloacetate transaminase (GOT) $(\mathrm{U} / \mathrm{l})$ & $25.9 \pm 9.2$ & $29.4 \pm 13.8$ & 0.17 \\
\hline Glutamopyruvate transferase (GPT) (U/I) & $29.8 \pm 22.3$ & $30.9 \pm 29.5$ & 0.39 \\
\hline Alcaline phosphatase $(\mathrm{U} / \mathrm{l})$ & $93.0 \pm 32.5$ & $84.4 \pm 34.8$ & 0.44 \\
\hline sCD14 (ng/ml) & $1939 \pm 440$ & $1756 \pm 806$ & $0.0087^{\mathrm{c}}$ \\
\hline Patients with high sCD14 ( $\geq 2000 \mathrm{ng} / \mathrm{ml})$ & $17(53.1)$ & $6(18.8)$ & $0.0042^{\mathrm{C}}$ \\
\hline Lipopolysaccharides (LPS) (pg/ml) & $22.8 \pm 12.3$ & $20.6 \pm 11.6$ & 0.53 \\
\hline Patients with high LPS $(\geq 25.0 \mathrm{pg} / \mathrm{ml})$ & $14(43.8)$ & $14(43.8)$ & 1.00 \\
\hline Lipopolysaccharide-binding protein (LBP) (ng/ml) & $1.9 \pm 2.2$ & $1.5 \pm 1.5$ & 0.43 \\
\hline Patients with high LBP $(\geq 4.1 \mathrm{ng} / \mathrm{ml})$ & $5(15.6)$ & $2(6.3)$ & $0.43^{\mathrm{b}}$ \\
\hline
\end{tabular}

${ }^{a}$ Wilcoxon rank-sum test.

${ }^{\mathrm{b}} \chi^{2}$ test or Fisher exact test.

Indicates in which aspects our populations are different.

CD14 is a coreceptor for LPS along with toll-like receptor-4 and myeloid differentiation factor-2 and is bound to the membrane by a gltcosyl phosphatidylinositol anchor. After exposure to bacterial endotoxin, monocytes release soluble CD14 (sCD14) by a proteasedependent shedding of the membrane form [4] but also by direct secretion of the soluble form $[5,6]$. Hepatocytes also produce sCD14 after LPS exposure by both mechanisms [7]. Accordingly, the increase of sCD14 has been described in $\mathrm{Gram}^{-}$bacterial sepsis [8] but also in other conditions associated with microbial translocation such as insulin resistance [9], liver inflammation [10], and cardiovascular diseases [11]. Several studies have also shown increased levels of sCD14 in HIV-infected patients with a good correlation with endotoxin levels [12-14] therefore establishing sCD14 as a potential surrogate marker for microbial translocation. Most importantly, from a nested case-control study performed on patients from the SMART trial, it was demonstrated that sCD14 is an independent marker of mortality [15].

The mechanisms underlying the increase of sCD14 are nevertheless complex as exposure to cytokines such as interleukin 6 (IL-6) and IL-1 $\beta$ is sufficient to trigger its release [16] suggesting that it is more a marker of monocyte activation than of microbial translocation. It is also known that the exposure to IL-6 releases sCD14 by the liver [17]. Importantly, ethnicity could also be a confounding factor weakening the link between sCD14 and microbial translocation. Reiner et al. measured sCD14 levels in more than 5000 non-HIV-infected individuals above 65year old living in the United States. Interestingly, sCD14 levels were lower in blacks. The authors estimated that genetic factors (i.e. differences in frequencies of CD14 alleles associated with its lower expression) could only explain $23 \%$ of this difference [18]. The objective of this study was to confirm these data in a mixed race population of HIV-infected patients living in Belgium.

\section{Material and methods}

The study was based on a sample of 64 chronically HIVinfected patients treated at the Liège AIDS Reference Center. There were 32 whites and 32 black Africans living in Belgium for at least 3 years (mean $\pm \mathrm{SD}$, $11.1 \pm 8.0$ years) and originating from Congo (DRC), Rwanda, Burundi, Cameroun, Ivory Coast, Guinea and Togo. The two ethnic groups were matched by age, sex and treatment. The Ethical Committee of the CHU of Liège approved the study protocol. Consent for participation was obtained in accordance with institutional review board standards.

\section{Microbial translocation biomarkers}

Direct [LPS and lipopolysaccharide-binding protein (LBP)] and indirect (sCD14) markers of microbial translocation were measured. LPS were measured using a Human LPS ELISA kit (Cusabio, Wuhan, China). Samples were measured according to the assay protocol. Samples were stored at $-80^{\circ} \mathrm{C}\left(193.15^{\circ} \mathrm{K}\right)$ after centrifugation. All the measurements were performed in the same run. sCD14 was measured by using enzyme-linked immunosorbent assay with the manufacturers' protocol (R\&D Systems, Minneapolis, Minnesota, USA) on $100 \mu \mathrm{l}$ of patient's serum (serum diluted to $0.5 \%$ ). LBP was quantified with the manufacturers protocol (Cusabio, Wuhan, China). 


\section{Statistical methods}

Ethnic groups were compared by the Wilcoxon rank-sum test for quantitative variables and the $\chi^{2}$ or Fisher exact test for qualitative findings. The Spearman correlation coefficient was calculated to measure the association between two quantitative variables. Calculations were computed on the maximum of available data, none missing values were replaced. Results were considered as significant at the $5 \%$ critical level $(P<0.05)$. The analyses were carried out using SAS (version 9.4; SAS Institute Inc., Cary, North Carolina, USA) and R (version 3.0.3) statistical packages.

\section{Results}

The two ethnic groups were similar for BMI, CD4, CD8, viral load, liver tests and cholesterol (Table 1). Triglycerides levels were higher in whites than in black African patients $(P=0.026)$ and so were sCD14 values $(1939 \pm 439$ vs. $1756 \pm 806 \mathrm{ng} / \mathrm{ml}, P=0.0087)$. High values of sCD14 (defined by a concentration higher than $2000 \mathrm{ng} / \mathrm{ml}$ ) were observed in $53.1 \%$ of whites and only in $18.8 \%$ of black Africans $(P=0.0042)$ (Fig. 1).

In contrast, LPS concentrations did not differ significantly between the two ethnic groups $(22.8 \pm 12.3$ vs. $20.6 \pm 11.6 \mathrm{pg} / \mathrm{ml}, \quad P=0.53)$ and the proportion of patients with concentrations above $25 \mathrm{pg} / \mathrm{ml}$ was comparable in both groups. Similarly, no difference was found regarding LBP concentrations $(1.9 \pm 2.2$ vs. $1.5 \pm 1.5 \mathrm{ng} / \mathrm{ml}, P=0.43)$ and proportions of patients with values above the cut-off level.
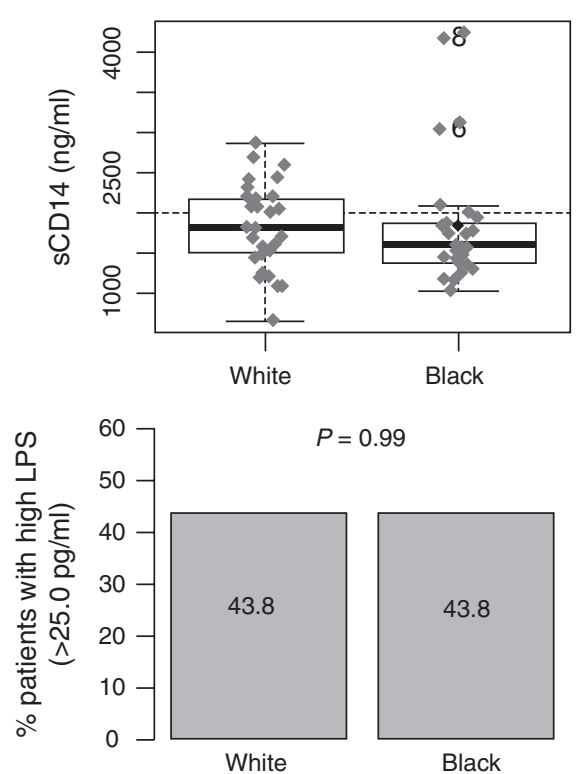

As expected, the correlation between LPS and LBP was strong $(r=0.79)$ and comparable in white $(r=0.79)$ and African patients $(r=0.78)$. Interestingly, the negative association between LPS and sCD14 was weaker in African patients $(r=-0.23)$ than in whites $(r=-0.38)$.

\section{Discussion}

Microbial translocation is a central mechanism of HIV pathogenesis as it links the tropism of the virus for mucosal $\mathrm{CD}^{+} \mathrm{T}$ cells to the long-term deleterious immune activation process associated with HIV infection. In addition to its role as a biomarker, sCD14 is also an actor in the inflammatory responses as it sensitizes tissues devoid of membrane CD14 such as endothelium [19] and platelets [20] to the effects of endotoxin. It is therefore logical that sCD14 stands as an independent marker of morbidity and mortality in various inflammatory processes including HIV infection.

In our study, we confirmed that HIV-infected Black Africans living in Belgium have lower levels of sCD14 when compared with a group of whites matched with respect to age, sex and CD $4^{+}$cell count. Different levels of microbial translocation could not explain this difference as endotoxin concentrations and LBP were similar in both groups. A recent study has shown that in the general population above 65 , sCD14 level is lower in black Africans, a difference only partially explained by genetics [18]. It is interesting to note that this also holds true in a younger population of HIV-infected individuals and in the context of microbial translocation, similar in

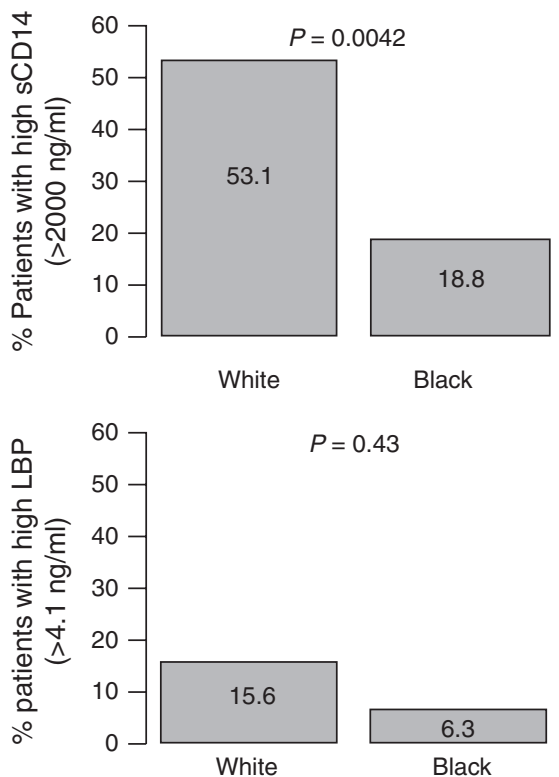

Fig. 1. Markers of microbial translocation according to ethnicity. High value of sCD14 (defined by a count $>2000 \mathrm{ng} / \mathrm{ml}$ ) is observed in $53.1 \%$ of white and in $18.8 \%$ of black ethnicity patients $\left(\chi^{2}, P=0.0042\right)$. Proportion of patient with high LPS value cannot be considered as different $\left(\chi^{2}, P=1.00\right)$. Proportion of patient with high LBP value cannot be considered as different (Fisher exact, $P=0.43)$. LBP, lipopolysaccharide-binding protein; LPS, lipopolysaccharide. 
both groups. Smoking was recently demonstrated to be associated with higher sCD14 levels in HIV-infected individuals [21]. In our study, the proportion of current smokers was indeed higher in Europeans than in black Africans. Different enterotypes, influenced by long-term dietary habits, could also intervene as the composition of intestinal microbiome also influences sCD14 levels in the context of HIV infection [22]. IL-6 is directly involved in the upregulation of sCD14 [16,17]. Interestingly, in untreated HIV-infected patients, IL-6 concentrations are lower in blacks than in whites [23]. As CRP levels were similar in our groups of treated patients, we do not believe that a difference in the concentration of IL-6 could explain our observation. Finally, it is interesting to note that association between LPS and sCD14 concentrations is weaker in the black African patients, confirming that sCD14 is not a direct marker of microbial translocation and that confounding factors, largely influenced by environmental conditions have to be taken into account for the interpretation of abnormal sCD14 concentrations.

\section{Acknowledgements}

\section{Conflicts of interest}

Competing interests statement: The authors declare that they have no competing financial interests.

\section{References}

1. Giorgi JV, Hultin LE, McKeating JA, Johnson TD Owens B, Jacobson $L P$, et al. Shorter survival in advanced human immunodeficiency virus type $\mathbf{1}$ infection is more closely associated with T lymphocyte activation than with plasma virus burden or virus chemokine coreceptor usage. I Infect Dis 1999; 179:859-870.

2. Brenchley JM, Price DA, Schacker TW, Asher TE, Silvestri G, Rao $S$, et al. Microbial translocation is a cause of systemic immune activation in chronic HIV infection. Nat Med 2006; 12:1365-1371.

3. Ndhlovu LC, Chapman JM, Jha AR, Snyder-Cappione JE, Pagán $M$, Leal FE, et al. Suppression of HIV-1 plasma viral load below detection preserves IL-17 producing T cells in HIV-1 infection. AIDS Lond Engl 2008; 22:990-992.

4. Bazil V, Strominger JL. Shedding as a mechanism of downmodulation of CD14 on stimulated human monocytes. / /mmunol Baltim Md 1991; 147:1567-1574.

5. Durieux JJ, Vita N, Popescu O, Guette F, Calzada-Wack J, Munker R, et al. The two soluble forms of the lipopolysaccharide receptor, CD14: characterization and release by normal human monocytes. Eur J Immunol 1994; 24:2006-2012.
6. Bufler P, Stiegler G, Schuchmann M, Hess S, Krüger C, Stelter F, et al. Soluble lipopolysaccharide receptor (CD14) is released via two different mechanisms from human monocytes and CD14 transfectants. Eur J Immunol 1995; 25:604-610.

7. Su GL, Dorko K, Strom SC, Nüssler AK, Wang SC. CD14 expression and production by human hepatocytes. I Hepatol 1999: 31:435-442.

8. Landmann R, Zimmerli W, Sansano S, Link S, Hahn A, Glauser $M P$, et al. Increased circulating soluble CD14 is associated with high mortality in gram-negative septic shock. J Infect Dis 1995; 171:639-644.

9. Fernández-Real JM, Broch M, Richart C, Vendrell J, LópezBermejo A, Ricart W. CD14 monocyte receptor, involved in the inflammatory cascade, and insulin sensitivity. / Clin Endocrinol Metab 2003; 88:1780-1784.

10. Oesterreicher C, Pfeffel F, Petermann D, Müller C. Increased in vitro production and serum levels of the soluble lipopolysaccharide receptor SCD14 in liver disease. / Hepato/ 1995; 23:396-402.

11. Longenecker CT, Jiang Y, Orringer CE, Gilkeson RC, Debanne S, Funderburg NT, et al. Soluble CD14 is independently associated with coronary calcification and extent of subclinical vascular disease in treated HIV infection. AIDS Lond Eng/ 2014; 28:969-977.

12. Abad-Fernández M, Vallejo A, Hernández-Novoa B, Díaz L, Gutiérrez C, Madrid N, et al. Correlation between different methods to measure microbial translocation and its association with immune activation in long-term suppressed HIV-1-infected individuals. J Acquir Immune Defic Syndr 2013; 64:149-153.

13. Marchetti G, Cozzi-Lepri A, Merlini E, Bellistrì GM, Castagna A, Galli $M$, et al. Microbial translocation predicts disease progression of HIV-infected antiretroviral-naive patients with high CD4+ cell count. AIDS Lond Eng/ 2011; 25:1385-1394.

14. León A, Leal L, Torres B, Lucero C, Inciarte A, Arnedo M, et al. Association of microbial translocation biomarkers with clinical outcome in controllers HIV-infected patients. AIDS Lond Engl 2015; 29:675-681.

15. Sandler NG, Wand H, Roque A, Law M, Nason MC, Nixon DE, et al. Plasma levels of soluble CD14 independently predict mortality in HIV infection. J Infect Dis 2011; 203:780-790.

16. Shive CL, Jiang W, Anthony DD, Lederman MM. Soluble CD14 is a nonspecific marker of monocyte activation. AIDS Lond Engl 2015; 29:1263-1265.

17. Bas S, Gauthier BR, Spenato U, Stingelin S, Gabay C. CD14 is an acute-phase protein. / Immunol 2004: 172:4470-4479.

18. Reiner AP, Lange EM, Jenny NS, Chaves PHM, Ellis J, Li J, et al. Soluble CD14: genomewide association analysis and relationship to cardiovascular risk and mortality in older adults. Arterioscler Thromb Vasc Biol 2013; 33:158-164.

19. Lloyd-Jones KL, Kelly MM, Kubes P. Varying importance of soluble and membrane CD14 in endothelial detection of lipopolysaccharide. I Immunol 2008; 181:1446-1453.

20. Damien P, Cognasse F, Eyraud M-A Arthaud C-A, Pozzetto B, Garraud O, et al. LPS stimulation of purified human platelets is partly dependent on plasma soluble CD14 to secrete their main secreted product, soluble-CD40-Ligand. BMC Immunol 2015; 16:3

21. Cioe PA, Baker J, Kojic E, Onen N, Hammer J, Patel P, et al. Elevated soluble CD14 and lower D-dimer are associated with cigarette smoking and heavy episodic alcohol use in persons living with HIV (PLWH). J Acquir Immune Defic Syndr 2015; 70:400-405.

22. Dinh DM, Volpe GE, Duffalo C, Bhalchandra S, Tai AK, Kane $\mathrm{AV}$, et al. Intestinal microbiota, microbial translocation, and systemic inflammation in chronic HIV infection. / Infect Dis 2015; 211:19-27.

23. Borges ÁH, O'Connor JL, Phillips AN, Rönsholt FF, Pett S, Vjecha MI, et al. Factors associated with plasma IL-6 levels during HIV infection. J Infect Dis 2015; 212:585-595. 